\title{
A NOÇÃO DE LIBERDADE NO EMÍLIO DE ROUSSEAU
}

Luiz Felipe Netto de Andrade e Silva SAHD ${ }^{1}$

- RESUMO: A educação natural de Rousseau é uma tentativa de mostrar como as paixões, se liberadas da deformação provocada pela opinião social, podem ser moralmente corretas. Se o Emílio, afirma Rousseau, é um tratado sobre a bondade natural do homem, esta bondade está fundada sobre a liberdade, e, sobretudo, sobre a liberdade das paixões.

- PALAVRAS-CHAVE: educação, bondade natural, liberdade.

Na Carta a Philibert Cramer, de 13 de outubro de 1764, Rousseau sugere que a análise atenta de seu pensamento filosófico deve ser empreendida a partir da leitura do Emílio (Rousseau, 1929, p.339). Segundo o autor, ele permite melhor compreender a ordem entre seus escritos e alcançar os princípios fundamentais de seu "sistema". Aceitando a indicação e o desafio proposto, o presente artigo tem como objetivo reconstruir argumentos centrais desenvolvidos por Rousseau acerca da constituição da noção de liberdade segundo o Emílio, isto é, segundo as duas etapas que caracterizam o seu conteúdo, a educação pela liberdade e a educação para a liberdade. ${ }^{2}$

1 Departamento de Filosofia - Universidade Federal de Uberlândia - MG - Brasil

2 Para Pierre Burgelin, é a tarefa mais árdua e demorada, pois repousa "sobre o que há de mais íntimo, e talvez de mais rebelde em nós". A aprendizagem da liberdade, conclui o comentador, "constitui nossa mais autêntica natureza de homem, e a mais recôndita. É ela que funda a virtude" (Burgelin, 1952, p.496). Cf., também, as análises sugestivas de Frédéric Worms (Worms, 2001, pp.5-18; pp.28-9), Yves Vargas (Vargas, 1995, pp.3-6) e Antonino Bruno (Bruno, 1997, pp.56-65). 
A proposição que inicia o capítulo primeiro do Contrato Social, "o homem nasceu livre e por toda parte se encontra sob grilhões" (Rousseau, 1964b, p.351), encontra o seu exemplo no Emílio. Nesse "romance da natureza humana", Rousseau tem como objetivo principal demonstrar que o homem da natureza, "saindo das mãos do Autor das coisas", difere radicalmente do homem civil, que "nasce, vive e morre na escravidão" (Rousseau, 1969a, p.63). Como se manifesta, pergunta o autor, a liberdade natural do homem? No âmbito físico, ela se identifica com a necessidade natural de movimento, cujos impedimentos à sua satisfação cria obstáculos ao desenvolvimento normal da criança e engendram efeitos físicos nefastos. Se a liberdade é um bem e a necessidade de movimento é a sua primeira manifestação, o uso "desnaturado" (dénaturé) da mesma representaria um excesso condenável, pois toda justificação desta prática não passaria de raciocínios inúteis da nossa falsa sabedoria jamais confirmados por nenhuma experiência. Nessa perspectiva, pode-se afirmar que uma educação adequada é aquela que respeita a liberdade física da criança. Nas palavras de Rousseau:

Da multidão de crianças que, entre povos mais sensatos do que nós, são criadas com toda a liberdade de seus membros, não se vê uma só que se fira ou se mutile; não dariam a seus movimentos a força que pudesse torná-los perigosos e, quando assumem uma posição violenta, a dor logo as adverte de que devem mudá-la. (Rousseau, 1969a, p.255-56)

Esta liberdade de movimento deve ser preservada quando a criança cresce, uma vez que os seus efeitos serão benéficos para o desenvolvimento de seu corpo (Rousseau, 1969a, p.278). Quando a criança conclui alguns progressos e as suas faculdades estão finalmente desenvolvidas, alcançando o estágio em que deveremos considerá-la um ser moral, sua verdadeira liberdade, segundo Rousseau, ultrapassa a liberdade inicial de movimento e se transforma numa liberdade da vontade. Mais exatamente, a criança é livre quando é capaz de realizar a sua vontade. Mas o que significa afirmar exatamente "fazer a sua vontade" (faire sa volonté)?

É, segundo o autor, ser capaz de bastar a si mesmo sem apresentar nenhuma dependência externa: "O que faz a sua vontade é aquele que não precisa para tanto colocar o braço de outrem na ponta dos seus. Segue-se daí que o primeiro de todos os bens não é a autoridade, mas a liberdade. O homem verdadeiramente livre só quer o que pode e faz o que lhe agrada. (Rousseau, 1969a, p.309) 
Se tal é a autêntica manifestação da liberdade, só o homem da natureza pode ser livre, pois tem forças suficientes para satisfazer as suas necessidades. Da sua fraqueza, a criança não goza da mesma vantagem, suas necessidades ultrapassam sempre as suas forças. Ela só pode, desse modo, usufruir "de uma liberdade imperfeita, semelhante àquela que gozam os homens no estado civil" (Rousseau, 1969a, p.310). Algumas crianças, porém, não parecem nem mesmo atingir esta liberdade imperfeita e vivem, por isso, numa espécie de escravidão em relação às suas necessidades e paixões. Mas este fenômeno não pode ser atribuído à natureza, a servidão que dela decorre é fruto de uma educação deficiente que não soube "distinguir com cuidado a verdadeira necessidade, a necessidade natural, da necessidade de fantasia que começa a nascer" (Rousseau, 1969a, p.312), acostumando a criança ao péssimo hábito de tudo adquirir sem nenhuma reserva.

No indivíduo humano que alcançou o estágio consciente e moral de seu desenvolvimento, a experiência da falta e do remorso seria, na visão de Rousseau, uma prova irrefutável da liberdade da vontade. É o que nos ensina o vigário em sua profissão de fé: "Quando me entrego às tentações, ajo conforme o impulso dos objetos externos. Quando me censuro por tal fraqueza, só ouço a minha vontade; sou escravo por meus vícios e livre por meus remorsos; o sentimento de minha liberdade só se apaga em mim quando me depravo e enfim impeço a voz da alma de se elevar contra a lei do corpo" (Rousseau, 1969a, p.586). Se do ponto de vista da essência, todavia, a liberdade da vontade é absoluta, do ponto de vista da existência, porém, ela não é exercida plenamente e pode mesmo desaparecer. De fato, na sua efetividade a vontade encontra novos obstáculos. São os elementos que constituem as necessidades e desejos dos indivíduos. O homem realmente livre faz tudo o que lhe agrada e convém, basta apenas deter os meios e adquirir a força suficiente para realizar os seus desejos. "Quem faz o que quer, diz Rousseau, é feliz quando basta a si mesmo" (Rousseau, 1969a, p.310). Esta auto-suficiência, assegurada ao homem no estado de natureza, é destruída pela sociedade corrompida que multiplica os desejos tornando-os ilimitados. A sociedade cria, assim, necessidades artificiais que Rousseau chama de fantaisie (Rousseau, 1969a, p.312). Qual liberdade poderia existir quando o homem, cujas forças são limitadas, se vê impotente diante das paixões de seus desejos? Ele pode, certamente, superar as suas forças com as forças dos outros; essa solução, no entanto, tem um alto preço, equivale a encontrar uma saída na própria servidão. Querer satisfazer suas necessidades artificiais significa submeter-se inevitavelmente à vonta- 
de dos outros. Esta lógica da dependência, alerta Rousseau, é habilmente explorada pelos governos constituídos (Rousseau, 1964a, p.7, nota).

Mesmo quando as necessidades não são obstáculos ao exercício da liberdade do indivíduo, ela só se realiza no momento em que, pelo viés das leis e de outras instituições, está submetida à vontade de outrem. No quadro da sociedade cujo fundamento é o contrato dos tolos (contrat de dupe), não é a vontade pública que prevalece a despeito de suas pretensões à generalidade. Ela é sempre a vontade particular ou de um indivíduo, ou de um grupo, ou de uma classe social. Para o autor do Contrato Social, a dependência à vontade particular constitui o pior dos males, e todo golpe à liberdade individual se resume na sua dominação por uma outra vontade particular. O selvagem do Discurso sobre a Desigualdade é livre, pois sua condição de vida lhe permite escapar, se nenhuma investida for feita por seus semelhantes, de toda tentativa de submissão. Ele, certamente, não escapa da dependência das coisas, mas ao contrário da dependência dos homens, aquela não é nem arbitrária nem desordenada (desordonnée) (Rousseau, 1969a, p.311). Ser livre não seria mais fazer o que se quer, mas sim, não estar submetido a uma vontade particular. Na primeira carta a Malesherbes, Rousseau tenta convencer seu interlocutor de que o desgosto pelo comércio dos homens, sobretudo no contexto da sociedade mundana, advém do fato de que esta última o obriga a fazer a vontade do outro, sendo, por isso, uma fonte de desregramentos e um golpe profundo em sua própria liberdade: "a espécie de felicidade que preciso", diz Rousseau, "não é fazer o que eu quero, mas não fazer o que não quero" (Rousseau, 1959b, p.1131). Não se trata, aqui, da expressão de sua idiossincrasia, por si mesma relativa, mas da concepção filosófica da liberdade individual de cujo teor não podemos desconhecer a originalidade: A liberdade, escreve Rousseau na oitava carta das Cartas escritas da Montanha

consiste menos em fazer sua vontade do que submeter-se à dos outros; consiste, ainda, em não submeter a vontade de outrem à nossa. Quem quer que seja mestre, não pode ser livre: reinar é obedecer. (Rousseau, 1964c, p.841) ${ }^{3}$

Escapamos a uma tal submissão quando as leis às quais obedecemos são todas tão impessoais e inflexíveis quanto as leis da natureza,

3 Rousseau mantém até o final esta posição, cf. o fragmento dos Devaneios do Caminhante Solitário: Je n'ai jamais cru que la liberté de l'homme consistat à faire ce qu'il veut, mais bien à ne jamais faire ce qu"il ne veut pas" (Rousseau, 1959a, p.1059). 
isto é, quando elas são a expressão da vontade geral. A república, assim, é o único regime político em que o indivíduo não deve temer uma dependência particular, pois ele é realmente livre:

Se as leis das nações pudessem ter, como as da natureza, uma inflexibilidade que nunca alguma força humana pudesse vencer, a dependência dos homens voltaria então a ser a das coisas; reunir-se-iam na república todas as vantagens do estado natural e do estado civil; juntar-se-ia à liberdade que mantém o homem sem vícios a moralidade que o educa para a virtude (Rousseau, 1969a, p.311).

Para Rousseau, contudo, os homens jamais viverão numa sociedade onde as leis positivas serão tão inflexíveis como as leis da natureza; eles podem, na melhor das hipóteses, receber uma educação que leve em consideração uma forma de liberdade que lhes é mais acessível e racional.

Em sua obra sobre a doutrina da educação de Rousseau, Francisque Vial identifica o princípio básico que exprime melhor a filosofia do Emílio: a educação deve ser, ao mesmo tempo, pela e para a liberdade (Vial, 1920, pp.111-12). A tese de Rousseau, segundo a visão de Vial, é simples: para um ser livre, a educação apropriada só pode ser a educação pela liberdade. Uma tal educação, além de ser a única pertinente, responderia às necessidades naturais da criança (Ravier, 1941, p.335). Ao longo do Emílio, Rousseau reitera incansavelmente a sua recomendação segundo a qual é preciso respeitar a liberdade da criança e criar à sua volta um clima propício para a sua reprodução. O respeito à liberdade, desse modo, deve ser presenciado desde os primeiros instantes em que a criança saiu do seio de sua progenitora (Rousseau, 1969a, p.278). Com o seu crescimento, a criança deve ganhar espaço para se deslocar com toda liberdade e praticar jogos que lhe possibilitem o exercício dos membros. Se há algum mal nessa atitude pedagógica, ele é negligenciável:

Em vez de deixá-lo estragar-se no ar corrompido de um quarto, que seja levado diariamente até um prado. Ali, que corra, se divirta, caia cem vezes por dia, tanto melhor, aprenderá mais cedo a se levantar. O bem-estar da liberdade compensa muitos machucados. (Rousseau, 1969a, p.301)

Esta educação pela liberdade rejeita o hábito, pois ele representa uma forma de servidão, e se desejamos que a criança mais tarde se 
comporte como um homem livre, é preciso que ela seja desde o início senhora de suas próprias necessidades. Segundo Rousseau:

o único hábito que devemos deixar que a criança pegue é o de não contrair nenhum. (...). Preparai à distância o reinado de sua liberdade e o uso de suas forças, deixando em seu corpo o hábito natural, colocando-a em condições de sempre ser senhora de si mesma e de fazer em todas as coisas a sua vontade, assim que a tiver. (Rousseau, 1969a, p.282)

No exato momento em que a criança adquire forças, e os preconceitos e a opinião dos outros podem atingir a sua alma, a educação deverá seguir um certo número de regras cujo espírito é "dar às crianças mais verdadeira liberdade e menos domínio, deixar que façam mais por si mesmas e exijam menos dos outros" (Rousseau, 1969a, p.290). Esta recomendação, aliás, se multiplica com uma relativa facilidade em várias passagens do Emílio (cf. Rousseau, 1969a, pp.324, 342, 422, 522, 539).

Esta educação pela liberdade é, ao mesmo tempo, uma educação para a liberdade. Para conduzir uma vida de homem livre é preciso superar as formas de dependência estabelecidas com os outros homens. Se a dependência em relação às coisas não é incompatível com a liberdade, a submissão aos seres da mesma espécie é um obstáculo que a anula. Como surge esta diferença de realidade que sugere duas espécies de dependência? Uma passagem bem conhecida do Livro II do Emílio parece explicá-la:

Existem dois tipos de dependência: a das coisas, que é da natureza, e a dos homens, que é da sociedade. Não tendo nenhuma moralidade, a dependência das coisas não prejudica a liberdade e não gera vícios; a dependência dos homens, sendo desordenada, gera todos os vícios, e é por ela que o senhor e o escravo depravam-se mutuamente. (Rousseau, 1969a, p.311)

Esta concepção permite compreender um dos traços particulares da educação do Emílio, é preciso oferecer um aprendizado sobre a necessidade e evitar as influências da opinião dos outros. A necessidade se apresenta inicialmente sob a forma das penas, isto é, das dores físicas que não devem ser economizadas à criança, uma vez que faz parte da própria condição humana (Rousseau, 1969a, pp.260-61). O bom educador não é aquele que torna a vida fácil à criança, não é tampouco aquele que pratica um modo de vida espartano, sem nenhuma consideração por seu ritmo de desenvolvimento (Rousseau, 1969a, p.313). 
O homem não pode pretender a condição da liberdade se a sua saúde e frágil felicidade dependerem inteiramente da situação histórica, social e meio particular em que vive. ${ }^{4}$ Ele só pode ser livre se permanecer invulnerável a toda mudança, transcendendo o fluxo e o refluxo da fortuna. A educação do Emílio lhe permite resguardar a tranqüilidade da alma e preservar o seu "lugar" em meio aos acontecimentos. É, assim, que o aluno imaginário aprende uma profissão e adquire a condição que o tornará imune às vicissitudes da fortuna. Da aprendizagem da necessidade, porém, resulta uma disposição da alma:

Que me importa, diz Emílio ao retornar de viagem, minha condição na terra? Em toda parte onde há homens, estou junto a meus irmãos; em toda parte onde não há homens, estou em casa. (.). Venha a morte quando vier, desafio-a, ela nunca me surpreenderá fazendo preparativos para viver; nunca me impedirá de ter vivido. (Rousseau, 1969a, p.857)

Assim sendo, a submissão à lei da necessidade é mais do que uma condição suficiente da vida livre, ela é uma condição inevitável, pois o homem só a adquire plenamente quando passa a controlar as suas paixões, quando ele se torna um ser virtuoso. E num mundo em que reina "o interesse particular e as paixões dos homens", esta liberdade interior é, aos olhos de Rousseau, a única liberdade autêntica. ${ }^{5}$ Ao fazer o balanço de suas observações e reflexões, o educador ressalta a sua importância:

Mas as leis eternas da natureza e da ordem existem. Para o sábio, são como uma lei positiva; são escritas no fundo do seu coração pela consciência e pela razão; é a elas que deve sujeitar-se para ser livre, e só é escravo quem age mal, pois fá-lo sempre contra a vontade. A liberdade não está em nenhuma forma de governo, ela está no coração do homem livre; ele a carrega consigo por toda parte. (Rousseau, 1969a, p.857)

Como preparar, no entanto, a criança para esse controle de si mesma, para essa liberdade moral? Para uma criança que não alcançou ainda a idade da razão, deve-se seguir a regra da necessidade. Só as necessidades naturais devem receber satisfação; as necessidades de

4 O termo frágil felicidade é tomado de empréstimo de Tzvetan Todorov (Todorov, 1985, pp.86-7).

5 É o que parece afirmar o mestre de Emílio quando exorta o seu discípulo a abandonar Sophie no ponto culminante da paixão: “Jusqu'ici tu n'étaits libre qu'en apparence; tu n'avais que la liberté précaire d'un esclave à qui l'on n'a rien commandé. Maintenant sois libre en effet; apprens à devenir ton propre maître; commande à ton coeur, ô Émile" (Rousseau, 1969a, p.818). 
"fantasia", ao contrário, devem ser impiedosamente reprimidas (Rousseau, 1969a, p.316). Para Rousseau, uma educação que simultaneamente confunde as diferentes espécies de necessidade e expõe as crianças aos menores anseios, faz nascer nela desejos cada vez mais variados, intensos, tornando-a "o mais vil dos escravos e a mais miserável das criaturas" (Rousseau, 1969a, p.314). Numa idade em que impera a fraqueza, a criança deve sentir a sua debilidade e perceber que os choramingos são inúteis e os gritos não se transformarão em ordens. Suas necessidades artificiais não podem encontrar nenhuma complacência por parte dos adultos, devem, isto sim, encontrar uma forte resistência que recusa, de maneira inflexível, a sua tiranização. Se a regra da necessidade é bem observada, a atitude de recusa se converte na própria necessidade das coisas, isto é, ela não assume um caráter de caprice des hommes. Ensinado numa tal atmosfera, o aluno torna-se-á "paciente, calmo, resignado, tranqüilo, mesmo quando não tiver obtido o que queria, pois faz parte da natureza do homem suportar pacientemente a necessidade das coisas, mas não a má vontade do outro" (Rousseau, 1969a, p.320).

Qual regra devemos adotar para um sujeito na idade da razão? Qual regra devemos seguir para educar Emílio quando descobre e conhece a primeira paixão? Compreender a lei da necessidade das coisas morais, eis a regra a seguir, responde Rousseau. É esta regra de conduta, de sabor estóico, ${ }^{6}$ que o educador propõe a Emílio antes de sua partida:

(...) se quiseres viver feliz e sabiamente (.). estende a lei da necessidade às coisas morais, aprende a perder o que te pode ser retirado; aprende a deixar tudo quando a virtude o ordena, a colocar-te acima dos acontecimentos, a afastar deles o teu coração antes que eles o dilacerem, a ser corajoso na adversidade, para nunca seres miserável, a ser constante em teu dever, para nunca seres criminoso. Então, serás feliz apesar da fortuna e prudente apesar das paixões. (Rousseau, 1969a, p.820) ${ }^{7}$

Diante desta filosofia da educação que prega o espírito da liberdade e afirma vigorosamente a liberdade humana em suas diversas formas, não parece exagerado ver no Emílio, do mesmo modo que um tratado da

6 A leitura mais interessante das fontes estóicas no pensamento de Rousseau que tenho conhecimento foi feita por Kennedy F. Roche, para o nosso caso em particular, cf. o capítulo 4 intitulado Émile, or the Natural Man in Society (Roche, 1974, pp.39-58).

7 Num fragmento da Carta a Beaumont, encontramos a mesma frase: (...) celui qui ne tient à rien de ce qui enchaîne le coeurs des hommes est partout libre. En quelque lieu qu'on le laisse vivre il ne reconnaît d'autres lois que celles du devoir et de la nécessité (Rousseau, 1969b, p. 1021). 
bondade natural, ${ }^{8}$ um verdadeiro "tratado da liberdade" (Kryger, 1978, p.73). Em suma, do Discurso sobre as Ciências e as Artes ao Emílio e ao Contrato Social, passando pelo Discurso sobre a Desigualdade, o pensamento de Rousseau manifesta uma constante: o humano no homem se define essencialmente pela liberdade. A liberdade é um princípio fundador e diretor da ação moral e política dos indivíduos. ${ }^{9}$ Embora o seu emprego foi utilizado em muitos modos e contextos distintos, que devem ser diferenciados para que o seu pensamento sobre essa complexa matéria seja plenamente entendido, a idéia de liberdade é central para a filosofia política de Rousseau (cf., Cullen, 1993, pp.3-30). Pois, escreve no Contrato Social, "renunciar à liberdade é renunciar à qualidade de homem, aos direitos da humanidade" (Rousseau, 1964b, p.356). Eis, na opinião de Jean Starobinski, a mensagem de Rousseau aos homens do século XVIII (Starobinski, 1946-9, p.285). Não é admirável, porém, ver Rousseau fazer a crítica das teorias das origens do político invocando o princípio da liberdade (Bachofen, 2002, pp.228-240).

SAHD, L. F. N. de A. e S. The notion of liberty in Rousseau's Emile. Trans/Form/ Ação, (São Paulo), v.28(1), 2005, p.109-118.

- ABSTRACT: Rousseau's natural education is an attempt to show how the passions, if freed from the deformation caused by social opinion, can be morally upright; if the Émile is, Rousseau say, a treatise on man's natural goodness, this goodness is based on his fredom, and especially on the freedom of the passions.

- KEYWORDS: education, natural goodness, freedom.

8 A bondade natural é a tese central do pensamento de Rousseau para Arthur M. Melzer (Melzer, 1990, pp.15-26). Antes dele, porém, Roger D. Máster já admitia o papel fundador da bonté naturelle para a compreensão da antropologia política de Rousseau: Since Rousseau considered man's natural goodness to be the central thesis of his works, the Emile appears to be the most philosophical analysis of Rousseau's fundamental principle (Master, 1976, p.3).

9 Em uma obra recente, Simone Goyard-Fabre retoma, em parte, a tese de Edna Kryger: En plaçant la responsabilité de l'homme au coeur de la politique, Rousseau a assigné à l'idée de liberté la vocation et la foction d'idée directrice et régulative. Certes, tout autant que Montesquieu, Rousseau savait la polysémie troublante de ce concept. Mais, avant Kant, il l'a assimilée clairement à la capacité d'autonomie qui est en l'homme une prérogative essentielle, fût-elle lourde à assumer. Or, l'idée de liberté-autonomie pût-elle (ou dût-elle) être envisagée de différents points de vue, elle est, selon Rousseau, l'unique príncipe tout ensemble fondateur et recteur de la politique (Goyard-Fabre, 2001, p.7). 


\section{Referências Bibliográficas}

BACHOFEN, B. La condition de la liberté. Rousseau, critique des raisons politiques. Paris: Payot, 2002.

BRUNO, A. Jean-Jacques Rousseau. La morale sensitiva o il materialismo del saggio. Milano: Franco Angeli, 1997.

BURGELIN, P. La philosophie de l'existence de J.-J. Rousseau. Paris: PUF, 1952.

CULLEN, D. E. Freedom in Rousseau's Political Philosophy. DeKalb: Northern Illinois University Press, 1993.

GOYARD-FABRE, S. Politique et philosophie dans l'auvre de Jean-Jacques Rousseau. Paris: PUF, 2001.

KRYGER, E. La notion de liberté chez Rousseau et ses répercussions sur Kant. Paris: Nizet, 1978.

MASTER, R. D. The Political Philosophy of Rousseau. Princeton. New Jersey: Princeton University Press, 1976.

MELZER, A. M. The Natural Goodness of Man. On the System of Rousseau's Thought. Chicago: The University of Chicago Press, 1990.

RAVIER, A. L'éducation de l'homme nouveau. Essai historique et critique sur le livre de l'Émile de Jean-Jacques Rousseau. Tomo 2. Issoudun: Spes, 1941.

ROCHE, K. F. Rousseau. Stoic \& Romantic. London: Methuen, 1974.

ROUSSEAU, J.-J. Les rêveries du promeneur solitaire. In: Euvres Complètes. Tomo I. Paris: Pléiade, Gallimard, 1959a.

Quatre lettres à M. Malesherbes. In: Euvres Complètes. Tomo I. Paris, Pléiade: Gallimard, 1959b.

. Discours sur les sciences et les arts. In: Euvres Complètes. Tomo III.

Paris: Pléiade, Gallimard, 1964a.

Du contrat social. In: Euvres Complètes. Tomo III. Paris: Pléiade, Gallimard, 1964b.

Lettres écrites de la montagne. In: Euvres Complètes. Tomo III. Paris: Pléiade, Gallimard, 1964c.

Émile ou de l'éducation. In: Euvres Complètes. Tomo IV. Paris: Pléiade, Gallimard, 1969a.

Lettres à Christophe de Beaumont. In: Fuvres Complètes. Tomo IV. Paris: Pléiade, Gallimard, 1969b.

Lettre à Monsieur Philibert Cramer. In: Correspondance Générale.

Tomo XI. Paris: Armand Colin, 1929.

STAROBINSKI, J. Compte rendu du Contrat social. In: Annales de la Société Jean-Jacques Rousseau. Tomo XXXI. 1946-1949.

TODOROV, T. Frêle bonheur. Essai sur Rousseau. Paris: Hachette, 1985.

VARGAS, Y. Introduction à l'Émile de Rousseau. Paris: PUF, 1995.

VIAL, F. La doctrine d'éducation de Jean-Jacques Rousseau. Paris: Delagrave, 1920.

WORMS, F. Émile ou de l'éducation. Livre IV. Jean-Jacques Rousseau. Paris: Ellipses, 2001. 